\title{
Pemanfaatan Analisis Jaringan Sosial Dalam Penentuan Centrality Dalam Pengembangan Web Berita Online
}

\author{
Fitra Ramadhan ${ }^{1}$ \\ 1'Information System Departement, Bina Darma University, Palembang, Indonesia \\ Email: 1fitraramadhan12345@gmail.com
}

\begin{abstract}
Abstrak
Revolusi digital selama berapa tahun terakhir ini meningkat pesat dan membuat perkembangan pada basis data. Perkembangan data tersebut sering terjadi beredar secara global. Data yang tersebar secara global dapat dikonsumsikan sebagai informasi terutama dalam media sosial. Media sosial Twitter merupakan salah satu media sosial yang sudah banyak digunakan di indonesia, dengan Data percakapan pada Twitter tersebut dapat dimanfaatkan sebagai sarana Informasi atau berita dan dapat juga dianalisis. Dengan penelitian ini memanfaatkan Basis Data pada media sosial twitter pada tweets yang diperoleh melalui API (Application Programming Interface). Dengan basis data tersebut merupakan untuk mewakili jaringan sosial antara pengguna, dan dengan menggunakan metode Social Network Analisys (SNA) karena untuk mencari tahu siapa saja pengguna yang menunjukkan pengaruh paling besar dalam penyebaran berita atau informasi dengan menggunakan suatu kata kunci dengan kata lain kedekatan dan hubungan dalam tweet. Software basis data dan Visualisasi menggunakan Gephi. Dalam menentukan aktor yang paling berpengaruh dalam Hastag \#Indonesia dihitung menggunakan Centrality yang terdiri dari degree Centrality, Betweeness Centrality, dan Closeness Centrality. Sampel yang digunakan dalam penelitian ini merupakan sebuah tweet yang didalam mention, retweet, maupun reply interaksi akun tersebut menggunakan \#Indonesia. Hasil penelitian ini yaitu terdapat 1064 node (akun) dan terdapat 1261 edges merupakan aktor yang terlibat dalam interaksi. Dalam tersebut ditemukan aktor atau akun yang paling berengaruh dalam jaringan \#Indonesia secara keseluruhan adalah akun bernama bob_bay.
\end{abstract}

Keta Kunci: Twitter,Basis Data Graph, Metode Social Network Analysis

\section{PENDAHULUAN}

Dengan perkembangan teknologi internet yang saat ini terjadi membuat banyak perubahan dan pengembangan terhadap ilmu pengetahuan, 
Vol. 1, No. 3, September 2020 e-ISSN: 2775-2496

https://journal-computing.org/index.php/journal-cisa/index

teknologi dan informasi. Teknologi informasi sudah menjadi kebutuhan membuat sumber mendapatkan informasi semakin besar dan cepat, sehingga informasi yang tersedia semakin banyak terdapat pada dunia maya. Tidak dapat dipungkiri saat ini perkembangan basis data sebagai teknologi data yang sangat dibutuhkan. Data yang bersikulasi secara global yang dijadikan informasi secara luas salah satunya adalah sosial media dan media berita [3][Kesalahan! Sumber referensi tidak ditemukan.].

Media berita saat ini mulai semakin lama menunjukkan sebuah peningkatan, perkembangan, dan perubahan yang cukup signifikan dari setiap tahunnya dan yang telah diketahui memiliki banyak ragam jenis media yang digunakan yang bermula dari media, radio, surat kabar, televisi, majalah, dan yang saat ini sedang naik daun menggunakan media online (berita online). Tapi media online saat ini masih banyak yang belum memiliki atau mengetahui dari mana sumber itu berasal dan apakah itu benar-benar kongkrit atau bersifat real atau bersifat hoax.

Sosial media yang memiliki Basis data salah satunya adalah media sosial Twitter. Dilihat dari Besarnya pertumbuhan pengguna twitter dari tahunke tahun berdampak terhadap semakin banyaknya data yang dihasilkan, fenomena ini disebut dengan fenomena Big Data.[7] Dari setiap tweets menurut Huberman, Romero dan Wu (2009) dalam penelitian mereka menjelaskan tentang interaksi dari setiap akun di twitter dengan interaksi sesungguhnya, mereka meneliti menyatakan bahwa sesungguhnya jumlah teman pada setiap akun twitter sekitar $13 \%$ dari jumlah yang mengikuti [16]. Oleh karena itu dari hal tersebut dapat dilihat perkembangan yang terjadi pada jumlah pengguna pada media sosial twitter,

Banyaknya pengguna Twitter yang menggunakan tweets tersebut, Dengan memanfaatkan jaringan sosial yang terjadi antar akun merupakan suatu ide pengembangan untuk sebuah web berita online dengan menggunakan jaringan sosial sebagai sumber dan visual penelusuran dan penyebaran sumber berita tersebut menggunakan metode Social network analisis(SNA) [7].

Metode Social Network Analysis (SNA) adalah merupakan metode pemetaan dan pengukuran hubungan di antara orang-orang, kelompok, organisasi, komputer atau badan informasi/pengetahuan serta pengolahan lainnya yang berada dalam jaringan dengan memanfaatkan 
Vol. 1, No. 3, September 2020 e-ISSN: 2775-2496

https://journal-computing.org/index.php/journal-cisa/index

teori graf [7]. Social network Analysis juga dapat membantu untuk memahami hubungan sosial yang melambangkan user dengan titik (node) dan hubungan antar user dilambangkan dengan (edges) [2].

Melihat permasalahan di atas, Social Network Analysis dalam suatu aplikasi yang mampu menggambarkan relasi atau hubungan antar individu dengan melakukan visualisasi dalam bentuk graf dengan menggunakan struktur jaringan sosial kiranya dapat membantu proses pemecahan masalah yang ada. Selain itu, akan dilakukan proses kalkulasi terhadap setiap relasi antar individu untuk menemukan centrality dari sebuah jejaring sosial yang didasarkan pada posisi masing-masing individu yang terkait dalam struktur jaringan. Dengan pengembangan ini, tiap individu dapat menganalisa jaringan sosial yang telah mereka bangun dan mengetahui centrality dari struktur jalinan relasi yang dimiliki oleh masing-masing individu. Metode ini sangat cocok untuk media sosial twitter yang di ikuti atau memvisualisasikan aktivitas suatu akun twitter [7].

\section{METODE PENELITIAN}

Pada tahapan penelitian ini masuk kedalam penelitian yang bersifat deskriptif, penelitian deskriptif merupakan penelitian yang berupa fakta. Peneliti menggunakan pendekatan Social Network Analysis atau Analisis Jaringan Sosial, yang dimaksud merupakan metode dimana data yang didapat kemudian memodelkan data tersebut dengan menggambarkan model interaksi dari sebuah aktor yang paling berpengaruh dalam bentuk Graph. dengan demikian metode ini dapat dilakukan dengan beberapa tahapan penelitian yang digambarkan pada gambar 1 Sebagai berikut:

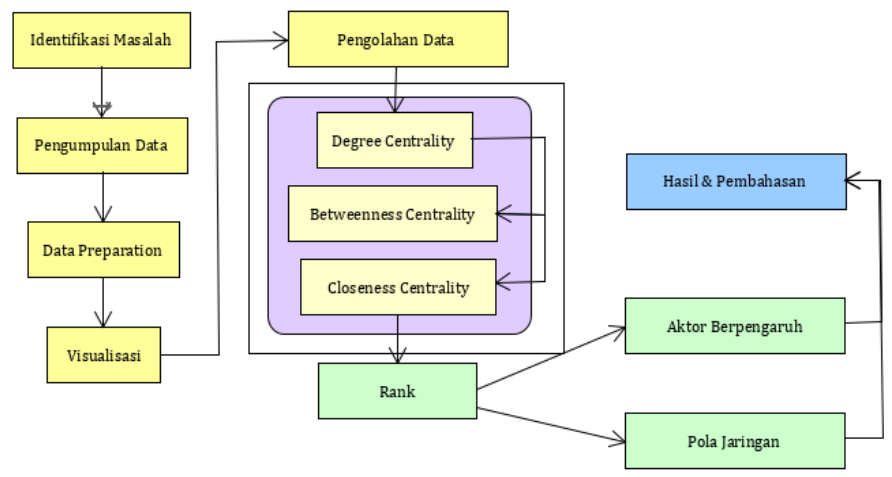

Gambar 1. Tahapan Penelitian 
Vol. 1, No. 3, September 2020 e-ISSN: 2775-2496

https://journal-computing.org/index.php/journal-cisa/index

Tahapan Penelitian dapat dijelaskan sebagai berikut :

1) Identifikasi masalah :

Pada tahap ini merupakan tahapan menentukan suatu masalah penelitian. Dalam Proses pengidentifikasian masalah dapat terlebih dahulu mengamati fenomena yang melatar belakangi penelitian agar penelitian bisa terlaksana [13].

2) Pengumpulan data:

Tahap ini bermula mengumpulkan data yang akan di teliti dengan mengambil sampel pada suatu tweets pada akun Twitter yang memposting dengan sebuah kata kunci hastag \#Indonesia dengan melakukan Crawling data menggunakan coding crawling yang disiapkan dengan format py (python).

3) Data Preparation :

Tahap ini merupakan tahap untuk pengolahan data excel yang diambil setelah meng-crawling data twitter yang berformat .json, kemudian meng-convert data tersebut menjadi .csv. kemudian data yang akan import harus terbagi 2 dataset csv, yaitu dataset node dan dataset edges [13].

4) Pengolahan Data:

Pengolahan yang dilakukan pada tahap ini menjelaskan interaksi jaringan yang terjadi. Setelah mengimport dua dataset tersebut kemudian memvisualisasikan data tersebut berformat Excel selanjutnya melakukan perhitungan nilai atribut pada jaringan yaitu menghitung tiga nilai Centrality (Degree Centrality, Betwenness Centrality, dan Closeness Centrality).

5) Perhitungan Nilai Centrality:

Pada tahap ini merupakan tahap perhitungan yang menghitung nilai centrality dengan untuk melihat nilai dari keseluruhan akun atau aktor dyang memiliki nilai tertinggi agar mengetahui aktor mana yang paling berpengaruh dalam nilai Degree Centrality, Betwenness Centrality, dan Closeness Centrality.

6) Rank:

Tahap ini merupakan tahap menunjukkan peringkat nilai centrality yaitu nilai Degree Centrality, Betwenness Centrality, dan Closeness Centrality yang sudah dihitung dengan mengambil lima dari setiap aktor dalam jaringan yang memiliki nilai tertinggi.

7) Hasil dan Pembahasan :

Tahap ini merupakan tahap terakhir dalam penelitian ini. Dengan menjelaskan hasil analisis dan visualisasi yang telah diteliti dengan bantuan software gephi setelah itu menyimpulkan data nilai property jaringan dan tiga nilai centrality adalah degree centrality, betweeneess 
Vol. 1, No. 3, September 2020 e-ISSN: 2775-2496

https://journal-computing.org/index.php/journal-cisa/index

centrality, closeness centrality. yang dihitung menggunakan metode Social Network Analysis dengan menunjukkan siapa aktor yang paling berpengaruh dalam pola penyebaran dan interaksi dalam jaringan suatu tweets dengan menggunakan kata kunci Hastag \#Indonesia. [13]

\subsection{Metode Centrality}

Dalam jaringan sosial dan teori graf, untuk menentukan node pada sentralitas network dapat dilakukan dengan menggunakan metode sentralitas dengan empat cara untuk mengukur suatu sentralitas degree centrality, betweenness centrality, closeness centrality, dan eigenvector centrality. [16] Tetapi dalam penlitian ini hanya akan menggunakan 3 cara perhitungan yaitu sebagai berikut :

\subsubsection{Degree Centrality}

Degree Centrality merupakan jumlah koneksi atau interaksi yang dimiliki suatu node. Untuk menghitung jumlah atau nilai dari degree centrality berdasarkan rumus node ni dapat dilakukan sebagai berikut:

$$
C D(N i)=d(N i)
$$

Note:

CD : Merupakan Degree Centrality

$\mathrm{Ni} \quad$ : Merupakan Jumlah Node i dalam jaringan

d(ni) : Merupakan banyaknya jumlah dalam node ni dalam melakukan interaksi dengan node lain.[1]

\subsubsection{Closseness Centrality}

Closseness Centrality merupakan jarak rata-rata dari node satu dengan node yang lainnya di dalam jaringan, dalam kata lain bahwa menghitung dan mengukur kedekatan node satu dengan node lain. Untuk menghitung pada node ini menggunakan rumus berikut :

Note :

$$
\mathrm{CC}(\mathrm{ni})=\left[\mathrm{N}-1 / \sum \mathrm{d}(\mathrm{ni}, \mathrm{nj})\right]
$$

CC(ni) : Merupakan jumlah node yang memiliki oleh Closseness

Centrality

$\mathrm{Ni} \quad$ : Merupakan jumlah node dalam jaringan

d(ni,nj): Jumlah yang menghubungkan jalur relasi terpendek [1] 
Vol. 1, No. 3, September 2020 e-ISSN: 2775-2496

https://journal-computing.org/index.php/journal-cisa/index

\subsubsection{Betwenness Centrality}

Betwenness Centrality merupakan seberapa sering suatu node dilewati dan dilalui sebuah node lain untuk menuju ke node lainnya. Dengan kata lain dapat di definisikan bahwa nilai ini menentukan peran suatu aktor yang menjadi sebuah penghubung imteraksi dalam network [1].

$$
\mathrm{CB}(\mathrm{ni})=\sum \mathrm{Gjk}(\mathrm{ni}) / \mathrm{gjk}
$$

Note :

CB (ni) : Merupakan jumlah node yang dimiliki oleh Betweeneess Centrality

Gjk(ni) : Merupakan node dengan jumlah jalur terpendek dari node j ke node $\mathrm{k}$ yang melewati node $\mathrm{i}$.

Gjk : Banyaknya jumlah jalur terpendek antara 2 buah node dalam network.

\subsection{Implementasi Crawling Data}

Tahap ini peneliti melakukan penarikan data Hastag dari media sosial Twitter memerlukan Customer key dan Consumer secret untuk mengelola Data tersebut. Oleh sebab itu dengan memanfaatkan Twitter Development dengan menggunakan sistem API (Application Programming Interface) agar mendapatkan key tersebut. Setelah mendapatkan Customer key dan Consumer secret proses penarikan Data Twitter dapat dilakukan, dengan menggunakan sebuah coding yang digunakan untuk menarik data Twitter dalam coding tersebut memerlukan API Key. Berikut ini merupakan hasil dari proses penarikan Data Twtiter. Data yang ditarik merupakan data dari kolom komentar maupun sebuah tweet yang direpost di media sosial twitter dengan menggunakan kata kunci \#Indonesia

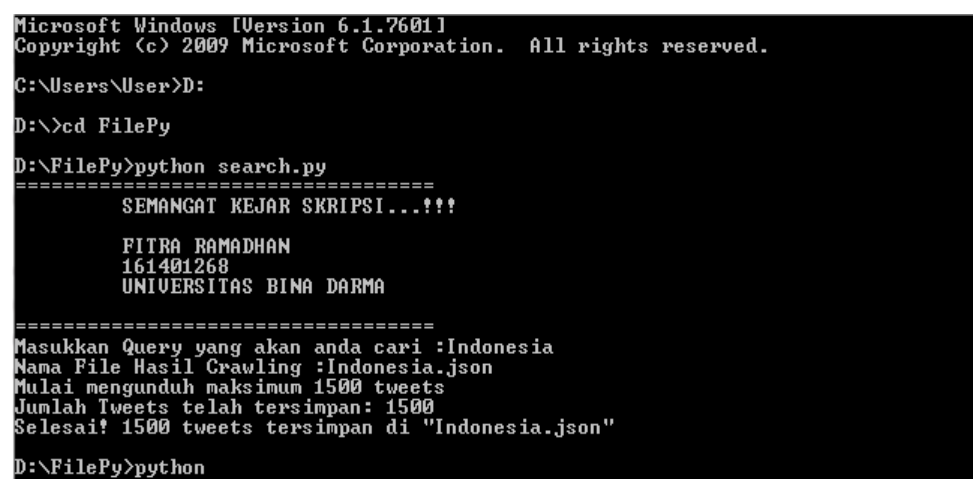

Gambar 2. Hasil Proses Penarikan data Twitter 
Vol. 1, No. 3, September 2020 e-ISSN: 2775-2496

https://journal-computing.org/index.php/journal-cisa/index

Pada Gambar diatas telah dilakukan penarikan dataset pada Twitter dengan mengambil dataset berjumlah 1500 data jaringan sosial dengan kata kunci Hastag \#indonesia. Berikut ini merupakan dataset yang sudah di crawling kemudian dataset tersebut di filter dimana data awal tersebut berjumlah 1500 data 1064 dataset yang tersisa. dengan mengambil dataset yang diperlukan untuk menganalisis jaringan sosial. Data yang diambil berupa From, To, Name, Id, Source, Target, Timeframe, Followers, Following, Start, dan End.

\begin{tabular}{|c|c|c|c|c|c|c|c|c|c|c|c|c|}
\hline 4 & A & B & c & D & E & $\mathrm{F}$ & G & H & I & & 1 & k \\
\hline 1 is & & from & to & Label & Source & Target & Followers & following & timeframe & & & end \\
\hline 2 & & 1 avishikaindofan & vrushymehta & avishikaindofan & 1 & 552 & 1291 & 1344 & & 1 & 03/08/2020 5:06 & 18/08/2020 1:11 \\
\hline 3 & & 2 avishikaindofan & bbbhumil & joanearls4 & 1 & 553 & 99 & 117 & & 1 & 03/08/2020 5:06 & $18 / 08 / 20201: 11$ \\
\hline 4 & & 3 joanear|s4 & detikcom & gdwtweets & 2 & 505 & 2646 & 3244 & & 2 & 03/08/2020 5:07 & $18 / 08 / 20201: 11$ \\
\hline 5 & & 4 joanearls4 & bbcindonesia & ucanews & 2 & 555 & 592 & 801 & & 2 & 03/08/20205:07 & 18/08/2020 1:11 \\
\hline 6 & & 5 joanearls4 & kemkominfo & daysneezes & 2 & 556 & 915 & 836 & & 2 & 03/08/2020 5:07 & $18 / 08 / 20201: 11$ \\
\hline 7 & & 6 joanearls4 & thejakartaglobe & ucanindia & 2 & 557 & 2276 & 1678 & & 2 & 03/08/2020 5:07 & 18/08/2020 1:11 \\
\hline 8 & & 7 joanearls4 & ganjarpranowo & ucanindonesia & 2 & 558 & 200 & 270 & & 2 & 03/08/20205:07 & 18/08/2020 1:11 \\
\hline 9 & & 8 joanearls4 & jokowi & ucansrilankä & 2 & 559 & 13 & 76 & & 2 & 03/08/2020 5:07 & 18/08/20201:11 \\
\hline 10 & & 9 joanearls4 & musarajekshah & harugontc_ina & 2 & 560 & 305 & 97 & & 2 & 03/08/2020 5:07 & $18 / 08 / 20201: 11$ \\
\hline 11 & & 10 joanearls4 & ridwankamil & mat_thompson & 2 & 561 & 234 & 2 & & 2 & 03/08/2020 5:07 & $18 / 08 / 20201: 11$ \\
\hline 12 & & 11 joanearls4 & khofifahip & vamamotopyumii & 2 & 562 & 3 & 16 & & 2 & 03/08/20205:07 & $18 / 08 / 20201: 11$ \\
\hline 13 & & 12 joanearls4 & ennindonesia & bonaboeabalpo & 2 & 563 & 43 & 10 & & 2 & 03/08/20205:07 & 18/08/2020 1:11 \\
\hline 14 & & 13 joanearls4 & tribunnews & vpenafreire & 2 & 564 & 9 & 20 & & 2 & 03/08/2020 5:07 & $18 / 08 / 20201: 11$ \\
\hline 15 & & 14 gdwtweets & endoceanplastic & aambros & 3 & 565 & 130 & 27 & & 3 & 03/08/2020 5:07 & $18 / 08 / 20201: 11$ \\
\hline 16 & & 15 gdwtweets & siegwerk_inks & crypto_milk & 3 & 566 & 1462 & 328 & & 3 & 03/08/2020 5:07 & 18/08/2020 1:11 \\
\hline 17 & & 16 avishikaindofan & bbbhumil & leevee6 & 1 & 553 & 20 & 215 & & 4 & 03/08/2020 5:09 & $18 / 08 / 20201: 11$ \\
\hline 18 & & 17 avishikaindofan & vrushyymehta & fuwafuwajjunhui & 1 & 552 & 30 & 320 & & 4 & 03/08/2020 5:09 & $18 / 08 / 20201: 11$ \\
\hline 19 & & 18 ucanews & roskarel & fauzianwar & 4 & 567 & 16362 & 2004 & & 5 & 03/08/2020 5:10 & 18/08/2020 1:11 \\
\hline 20 & & 19 ucanews & innewsid & siompay & 4 & 568 & 728 & 377 & & 5 & 03/08/2020 5:10 & $18 / 08 / 20201: 11$ \\
\hline 21 & & 20 ucanews & indonews9 & sayang_tua & 4 & 569 & 37092 & 1422 & & 5 & 03/08/2020 5:10 & 18/08/20201:11 \\
\hline 22 & & 21 daysneezes & langitrty & hannabiramochi_ & 5 & 570 & 1995 & 2172 & & 6 & 03/08/2020 5:10 & 18/08/2020 1:11 \\
\hline 23 & & 22 ucanindia & roskarel & youc1000vitamin ${ }^{-}$ & 6 & 56 & 390 & 90 & & 7 & 03/08/2020 5:11 & $18 / 08 / 20201: 11$ \\
\hline 24 & & 23 ucanindonesia & roskarel & oliatwit & 7 & 56 & 73629 & 1 & & 7 & 03/08/2020 5:11 & $18 / 08 / 20201: 11$ \\
\hline 25 & & 24 ucansrilanka & roskarel & hidsaljamil & 8 & 56 & 401 & 2637 & & 7 & $03 / 08 / 20205: 11$ & $18 / 08 / 20201: 11$ \\
\hline 26 & & 25 harugonff_ina & haruka_nkgw10 & itsmespicaa & 9 & 571 & 3648 & 39 & & 8 & $03 / 08 / 20205: 25$ & 18/08/2020 1:11 \\
\hline 27 & & 26 mat_thompson & endoceanplastic & agamanentity & 10 & 565 & 99168 & 5867 & & 9 & 03/08/2020 5:26 & 18/08/2020 1:11 \\
\hline & P & Data Fillter & (†) & & & & & & & & 1 & \\
\hline
\end{tabular}

Gambar 3. Hasil Dataset yang sudah diFilter

Setelah difilter dibuat menjadi 2 file untuk di export kedalam software Gephi. File tersebut adalah file node dan file edges. Berikut contoh 2 dataset tersebut.

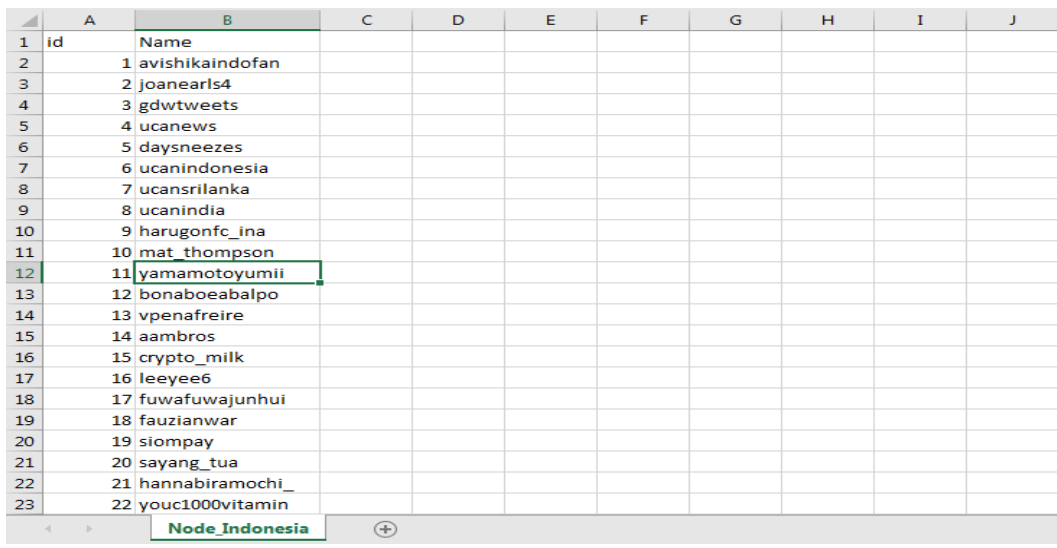

Gambar 4. Tampilan Dataset Node 
Vol. 1, No. 3, September 2020 e-ISSN: 2775-2496

https://journal-computing.org/index.php/journal-cisa/index

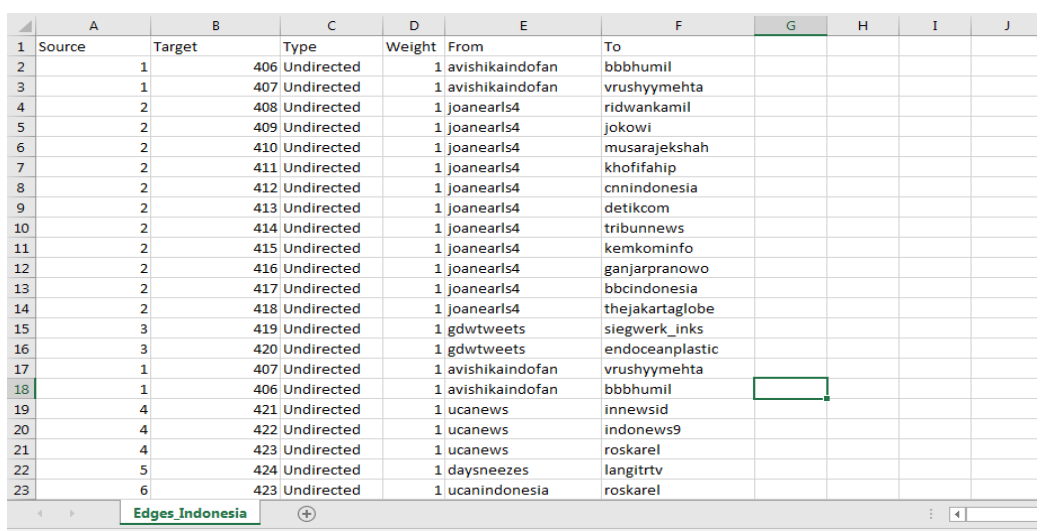

Gambar 5. Tampilan Dataset Edges

\section{HASIL DAN PEMBAHASAN}

\subsection{Hasil visualisasi}

Berikut ini merupakan hasil observasi terhadap Social Network Analysis (SNA) dengan menggunakan bantuan software Gephi.0.9.2. observasi ini menggunakan media sosial Twitter sebagai objek dengan menggunakan sebuah kata kunci Hastag \#Indonesia sebagai data yang ditarik. Data yang ditarik dan sudah difilter memiliki jumlah Nodes 1064 data dan Edges 1261 data. Graph Jaringan ini memiliki tipe bersifat Undirected, merupakan jenis graf yang tidak memiliki arah dalam interaksinya. Berikut ini merupakan gambar Visualiasi jaringan abstrak dan jaringan dengan hastag \#Indonesia.

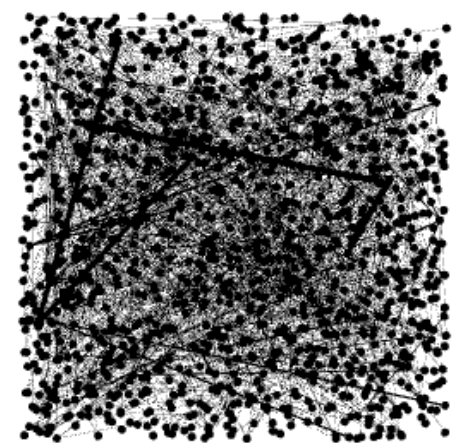

Gambar 6. Tampilan Visualisasi jaringan abstrak \#Indonesia 
Gambar 7. Tampilan Visualisasi jaringan \#Indonesia

\subsection{Properti jaringan}

Pada properti jaringan memiliki sebuah hasil dari nilai-nilai yang didapat pada properti jaringan yang terjadi pada dataset \#indonesia. Berikut hasil tabel properti jaringan tersebut:

Tabel 1. Tabel Properti Jaringan \#Indonesia

\begin{tabular}{lll}
\hline No. & \multicolumn{1}{c}{ Properti jaringan } & Nilai \\
\hline 1. & Size & Node $: 1064$ \\
& Density $: 1261$ \\
2. & Modularity & 0,001 \\
3. & Diameter & 0,957 \\
4. & Average Degree & 16 \\
5. & Average Path Lenght & 1,874 \\
6. &
\end{tabular}

\subsection{Analisis Centrality}

Pada Analisis Centrality ini bertujuan agar menemukan aktor yang paling berperan atau berpengaruh dalam sebuah jaringan (Network). Dalam hal itu Metric yang dapat digunakan untuk menentukan Centrality adalah Degree centrality, closeness centrality, dan betweenness centrality. 
Vol. 1, No. 3, September 2020 e-ISSN: 2775-2496

https://journal-computing.org/index.php/journal-cisa/index

Software Gephi merupakan salah satu alat yang dapat membantu menhitung ke-empat metric tersebut. Berikut hasil penelitian dari total perhitungan analisis Centrality :

\section{a. Degree Centrality}

Pada Analisis degree centrality ini berguna untuk menentukan aktor yang paling berperan berdasarkan banyaknya edges atau hubungan interaksi yang terjadi antar node yang satu dengan node lainnya. Berikut tabel dengan lima aktor dengan nilai peringkat yang memiliki degree centrality yang tertinggi:

Tabel 2. Dataaset nilai Degree Centrality

\begin{tabular}{lll}
\hline Id & Label & Nilai Degree \\
\hline 113 & bob_bay & 48 \\
228 & anuindonesia & 39 \\
229 & acopatunru & 34 \\
422 & menjelajahfajr & 23 \\
442 & mohammed_aak & 23 \\
\hline
\end{tabular}

Berdasarkan tabel diatas, maka didapatkannya sebuah kesimpulan bahwa akun twitter atau aktor yang paling berpengaruh adalah akun bernama bob_bay, dengan memiliki nilai Degree centrality sebesar 48, diikuti oleh akun bernama anuindonesia dengan nilai 39, akun bernama acopatunru dengan nilai 34 , aktor bernama menjelajahfajr dengan nilai 23, dan aktor mohammed_aak dengan nilai 23. Hal itu diidentifikasikan bahwa lima aktor tersebut merupakan aktor yang memiliki hubungan yang sangat kuat dalam setiap aktor.

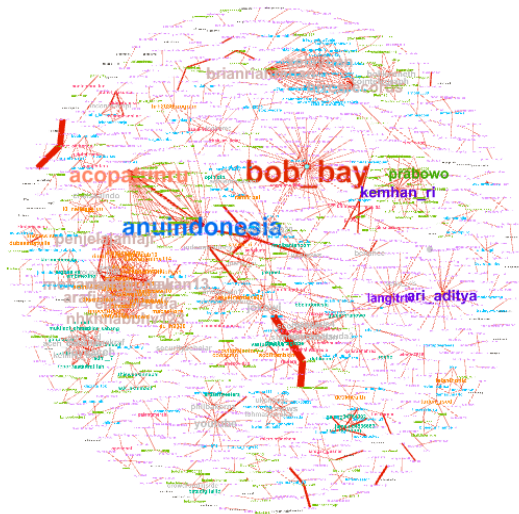

Gambar 8. Tampilan Visualisasi Degree Centrality 
Vol. 1, No. 3, September 2020 e-ISSN: 2775-2496

https://journal-computing.org/index.php/journal-cisa/index

\section{b. Betweenness Centrality}

Pada Analisis Betweenness Centrality ini berguna menentukan seberapa sering suatu node dilewati dan dilalui sebuah node lain untuk menuju ke node lainnya dan untuk mengetahui posisi atau letak Node didalam suatu network dimana node tersebut tidak boleh kosong atau hilang, karena jika tidak ada node maka akan terjadi suatu kesalahan dalam interaksi yang terjadi dalam jaringan. Berikut tabel lima aktor dengan nilai peringkat aktor Betweenness Centrality yang tertinggi

Tabel 3. Dataset nilai Betwenness Centrality

\begin{tabular}{lll}
\hline Id & Label & Nilai Betweenness Centrality \\
\hline 559 & jokowi & 14.025 .989 \\
185 & bob_bay & 12.366 .001 \\
318 & sara31142030 & 10.604 .299 \\
706 & sandiuno & 9.990 .944 \\
658 & menlu_ri & 4.114 .333 \\
\hline
\end{tabular}

Berdasarkan tabel diatas, maka didapatkannya sebuah kesimpulan bahwa akun twitter atau aktor yang paling sering dilewati node lainnya adalah akun bernama jokowi, dengan memiliki nilai Betweeneess centrality sebesar 14.025.989, kemudian diikuti aktor dengan nama akun bob_bay sebesar 12.366.001, akun bernama sara31142030 dengani nilai 10.604.299, akun bernama sandiuno dengan nilai 9.990.944, dan akun bernama menlu_ri dengan nilai sebesar 4.114.333. hal ini mengidentifikasikan bahwa 5 aktor tersebut merupakan aktor favorit didalam jaringan karena memiliki kemampuan sebagai perantara dan penghubung bagi banyak aktor lain.

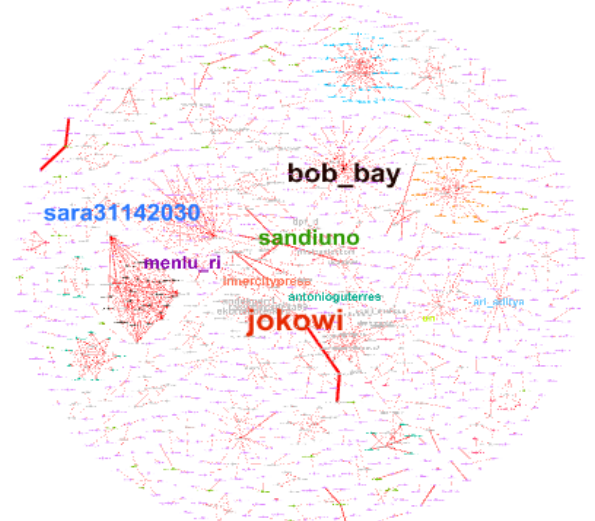

Gambar 9. Tampilan Visualisasi Betweenness Centrality 
Vol. 1, No. 3, September 2020 e-ISSN: 2775-2496

https://journal-computing.org/index.php/journal-cisa/index

\section{c. Closenness Centrality}

Pada Analisis Closenness Centrality ini berguna untuk mengukur kecepatan koneksi dengan menghitung jarak terpendek dari aktor ke semua aktor lainnya dalam suatu jaringan. Berikut tabel lima aktor dengan nilai peringkat aktor Closeneess Centrality yang tertinggi :

Tabel 4. Dataset nilai Closenness Centrality

\begin{tabular}{cll}
\hline Id & Label & Nilai Closeneess Centrality \\
\hline 631 & youtube & 0.941176 \\
228 & acopatunru & 0.880952 \\
800 & kemhan_ri & 0.866666 \\
921 & prabowo & 0.684211 \\
942 & Groupps_indo & 0.58 \\
\hline
\end{tabular}

Berdasarkan tabel diatas, maka didapatkannya sebuah kesimpulan bahwa akun twitter atau aktor yang dapat menjangkau node node lainnya yang mempunyai jalur terpendek dalam interaksi. Hal itu terdapat pada akun bernama youtube dengan nilai closenness centrality 0.941176, diikuti oleh akun bernama acopatunru dengan nilai 0.880952, akun bernama kemhan_ri dengan nilai 0.866666 , akun bernama prabowo dengan nilai 0.684211 , dan akun bernama groupps_indo dengan nilai 0.58 .

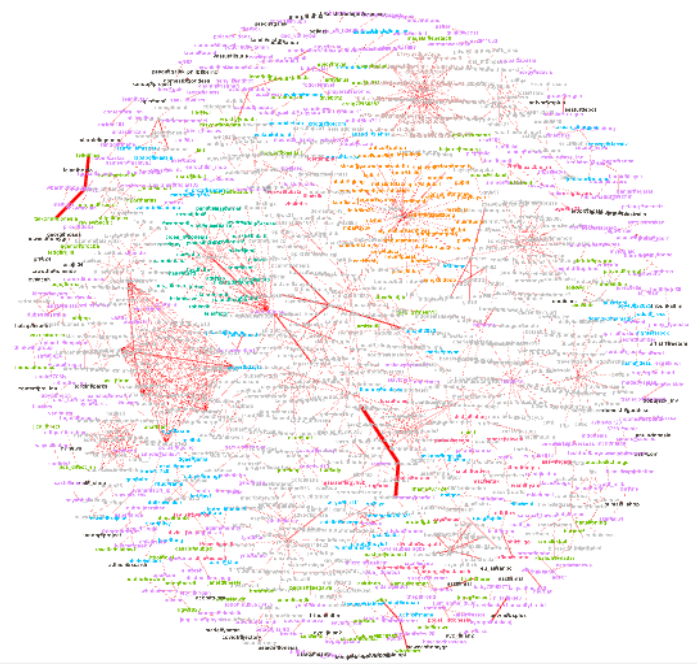

Gambar 10. Tampilan Visualisasi Closenness Centrality 
Journal of Computer and Information Systems Ampera

Vol. 1, No. 3, September 2020 e-ISSN: 2775-2496

https://journal-computing.org/index.php/journal-cisa/index

\subsection{Visualisasi Analysis Sosial Network (SNA) dalam Web Berita Online}

Pada penelitian ini, hasil dari nilai dan visualisasi dari Social Network Analysis (SNA) akan diintergrasikan kedalam sebuah web berita online. Berikut contoh SNA yaang sudah terintergrasi dalam web berita online.

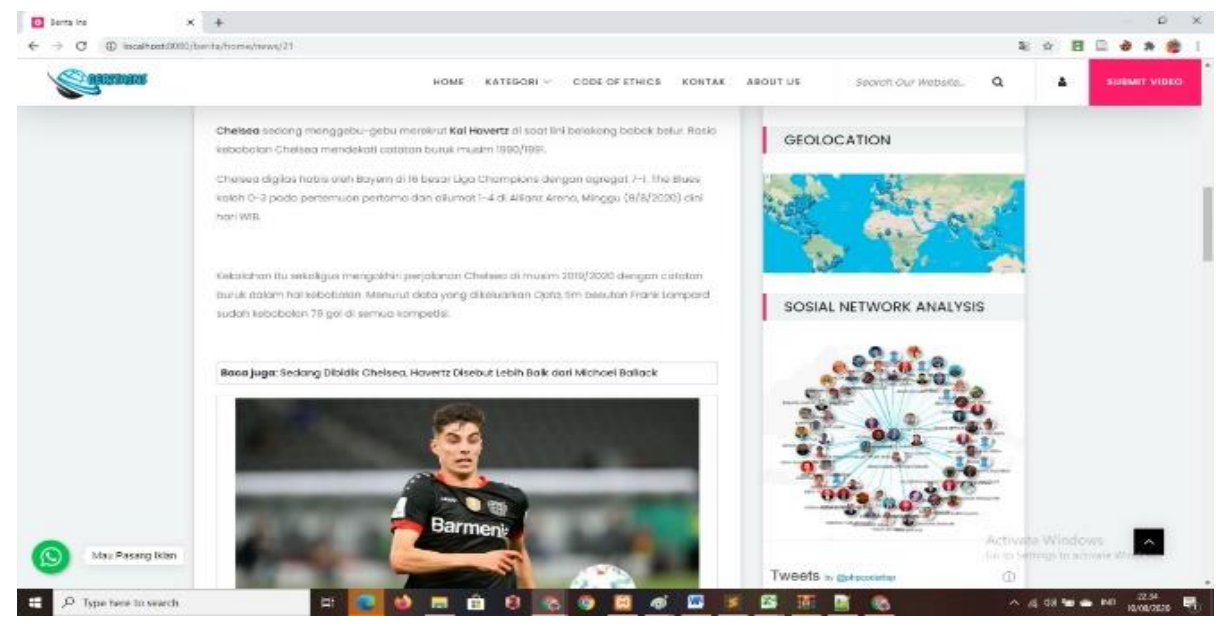

Gambar 11. Tampilan Web Berita Online Terintergrasi SNA

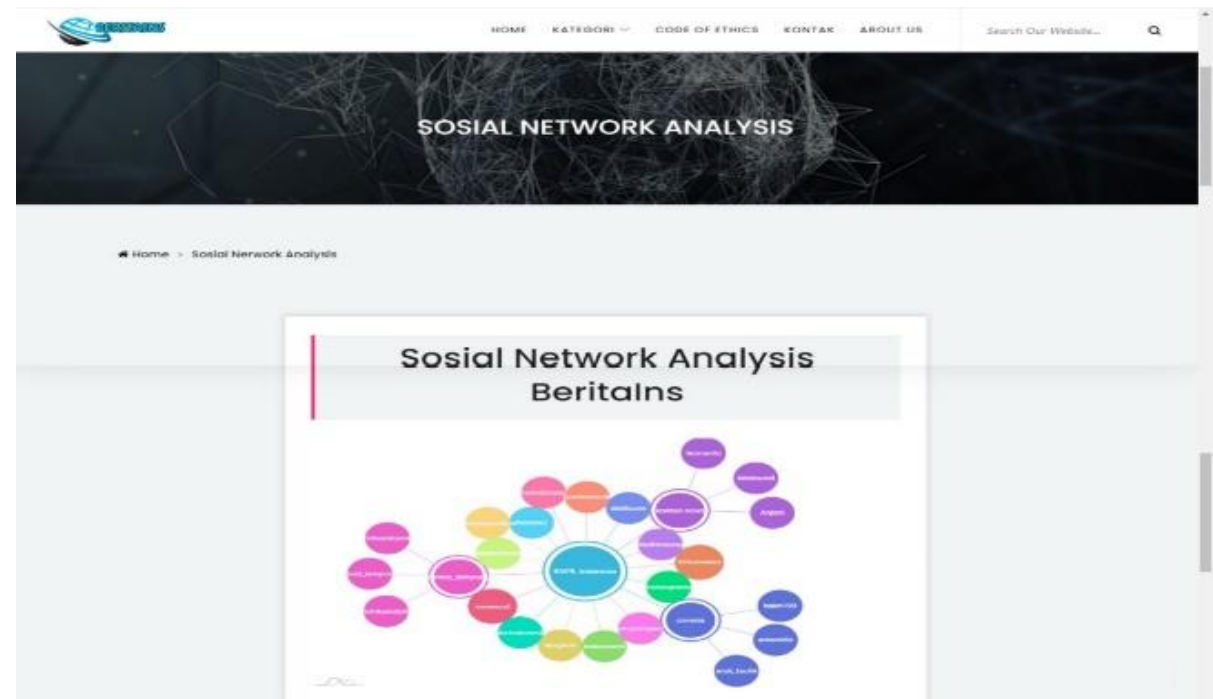

Gambar 12. Tampilan SNA dalam Web Berita Online 
Vol. 1, No. 3, September 2020 e-ISSN: 2775-2496

https://journal-computing.org/index.php/journal-cisa/index

Tampilan Visualisasi Social Network Analysis (SNA) diatas merupakan salah satu hasil skripsi peneliti lain yang merupakan satu kesatuan pada tema skripsi ini, dimana peneliti menggunakan dataset jaringan sosial yang sudah diberikan oleh peniliti, dataset tersebut digunakan agar menunjukkan aktor atau akun yang memiliki pengaruh besar dalam penyebaran berita trending tersebut, dan menggambarkan pola jaringan aktor tersebut dalam web berita online. Dengan menampilkan jaringan dan pola sosial tersebut menjadi lebih menarik.

\section{KESIMPULAN}

Dari hasil penelitian ini berdasarkan analisis sosial pada jaringan dataset \#indonesia dari media sosial Twitter dengan tipe graf Undirected, dapat disimpulkan bahwa:

1) Terdapat 1064 node akun dalam jaringan dataset \#indonesia dan Edges 1261 yang melakukan interkasi dalam jaringan tersebut

2) Bahwa perhitungan Centrality pada Social Network menggunakan media sosial Twitter untuk melihat aktor atau akun yang paling berpengaruh dalam interaksi, maupun penyebaran koneksi merupakan solusi dalam proses perhitungan dalam penentuan Central dari suatu jaringan sosial.

3) Dari hasil jaringan sosial dengan menggunakan metode Social Network Analysis (SNA) dengan hasil perhitungan properti jaringan yang terdiri dari : size, diameter, modularity, averagee degree, dan averagee path lenght.

4) Node atau aktor yang memiiki peran paling berpengaruh dalam jaringan sosial dengan kata kunci \#indonesia diambil kesimpulan bahwa secara keseluruhan adalah aktor bernama bob_bay. Aktor ini memiliki peringkat tertinggi pada Degree Centrality, peringkat ke dua dalam Betweeneess Centrality.

5) Hasil dari Nilai perhitungan Centrality menggunakan metode Social Network analysis (SNA), Dataset jaringan sosial tersebut dapat berguna untuk suatu pengembangan pada web berita online, dengan menggunakan jaringan sosial pada suatu berita pembaca, atau pengunjung dapat mengetahui siapa aktor atau akun yang berpengaruh dalam penyebaran dan menjembatani interaksi dalam berita tersebut.

6) Menggunakan data jaringan sosial tersebut pada suatu berita pada web berita online juga untuk menghindari suatu berita yang bersifat HOAX. 
Vol. 1, No. 3, September 2020 e-ISSN: 2775-2496

https://journal-computing.org/index.php/journal-cisa/index

\section{DAFTAR PUSTAKA}

[1] Sugiarta Ahmad Isnaini, Syamsuar Dedy, and Surya Negara Edi. Analisis sentralitas aktor pada struktur jaringan politik dengan menggunakan metode social network analysis (sna): Studi kasus group facebook lembaga survei sosial media. In Seminar Nasional Teknologi Informasi dan Komunikasi (SEMNASTIK) X, 2018.

[2] Made Kevin Bratawisnu and Andry Alamsyah. Social network analysis untuk analisa interaksi user di media sosial mengenai bisnis e-commerce. SOSIOHUMANITAS, 21(1):63-69, 2019.

[3] Fifit Fitriansyah. Efek komunikasi massa pada khalayak (studi deskriptif pengguna media sosial dalam membentuk perilaku remaja. Cakrawala-Jurnal Humaniora, 18(2):171-178, 2018.

[4] Asep Id Hadiana and Wina Witanti. Analisis jejaring sosial menggunakan social network analysis untuk membantu social crm bagi umkm di cimahi. 2017.

[5] Ihsan Imaduddin, Azhar, Program Studi, and Teknik Informatika. Teknologi basis data berorientasi graf. 2120.

[6] Dita Kusumasari and Onny Rafizan. Studi implementasi sistem big data untuk mendukung kebijakan komunikasi dan informatika. Masyarakat Telematika Dan Informasi: Jurnal Penelitian Teknologi Informasi dan Komunikasi, 8(2):81-96, 2018.

[7] Edi Surya Negara, Ria Andryani, and Prihambodo Hendro Saksono. Analisis data twitter: Ekstraksi dan analisis data g eospasial. Jurnal INKOM, 10(1):27, nov 2016.

[8] SOCIAL NETWORK, ANALYSIS UNTUK, ANALISA INTERAKSI, USER, DIMEDIA, SOSIAL MENGENAI, and BISNIS E-COMMERCE. Jurnal manajemen dan bisnis (almana) vol. 2 no.2 /agustus. 2018.

[9] Athifah Nurshafa and Andry Alamsyah. Analisis peringkat brand pada jejaring sosial percakapan menggunakan metode social network analysis (studi kasus brand alfamart dan indomaret pada media sosial twitter indonesia). eProceedings of Management, 3(3), 2016.

[10] Rio Oktora and Andry Alamsyah. Pola interaksi dan aktor yang paling berperan pada event jgtc 2013 melalui media sosial twitter (studi menggunakan metode social network analysis). Jurnal Manajemen Indonesia, 14(3):201-209, 2014.

[11] Yuni Rafita. Social network analysis dalam melihat kecenderungan pemberitaan pada akun twitter â€œ@detikcomâ€? dan â€œ@ metro_tvâ€?. Khazanah: Jurnal Mahasiswa UII, 6(2):67-81, 2014. 
Vol. 1, No. 3, September 2020 e-ISSN: 2775-2496

https://journal-computing.org/index.php/journal-cisa/index

[12] MM Ria Andryani, M Kom, MM Ria Andryani, M Kom, Surya Negara Edi, et al. Network of friends to the other friends by social media on facebook. The Turkish Online Journal of Design, Art and Communication, 12(12):1363-1378, 2017.

[13] Mahdi Shiddieqy Setatama and Dodie Tricahyono. Implementasi social network analysis pada penyebaran country branding â€œwonderful indonesiaâ€国. Indonesia Journal on Computing (IndoJC), 2(2):91-104, 2017.

[14] Muhammad Sholeh, RR Yuliana Rachmawati, and Erma Susanti. Pemodelan basis data graph dengan neo4j (studi kasus: Basis data sistem informasi penjualan pada umkm). Jurnal Teknologi Informasi dan Terapan (J-TIT), 7(1):25-32, 2020.

[15] Asri Sulistiawati, DP Lubis, and ES Mulyani. Analisis jaringan sosial dalam gabungan kelompok tani (gapoktan) tani berkah. Sodality: Jurnal Sosiologi Pedesaan, 2(02):76-82, 2014.

[16] Budi Susanto, Herlina Lina, and Antonius Rachmat Chrismanto. Penerapan social network analysis dalam penentuan centrality studi kasus social network twitter. Jurnal Informatika, 8(1), 2012.

[17] Maksim Tsvetovat and Alexander Kouznetsov. Social Network Analysis for Startups: Finding connections on the social web. " O'Reilly Media, Inc.", 2011.

[18] Panji Wisnu Wirawan and Djalal Er Riyanto. Kajian implementasi graph database pada rute bus rapid transit. Jurnal Nasional Teknologi dan Sistem Informasi, 3(3):313-319, 2017.

[19] Irma Yuliana, Paulus Insap Santosa, and Noor Akhmad Setiawan. Analisis jejaring media sosial untuk pemetaan pada komunitas online. Jurnal Fakultas Hukum UII, 2015.

[20] Sugiarta Ahmad Isnaini, Syamsuar Dedy, and Surya Negara Edi. Analisis sentralitas aktor pada struktur jaringan politik dengan menggunakan metode social network analysis (sna): Studi kasus group facebook lembaga survei sosial media. In Seminar Nasional Teknologi Informasi dan Komunikasi (SEMNASTIK) X, 2018.

[21] Tata Sutabri, Agung Suryatno, Dedi Setiadi, and Edi Surya Negara. Improving nave bayes in sentiment analysis for hotel industry in indonesia. Ïn 2018 Third International Conference on Informatics and Computing (ICIC), pages 1-6. IEEE, 2018.

[22] Edi Surya Negara. Kajian terhadap tools dan framework social media analytics untuk pemanfaatan data social media dalam penelitian ilmu sosial. Jurnal Teknologi Technoscientia, pages 132-138, 2017.

[23] Ahmad isnaini Sugiarta, Edi Surya Negara, et al. Analisis sentralitas aktor pada struktur jaringan politik dengan menggunakan metode 
https://journal-computing.org/index.php/journal-cisa/index

social network analysis (sna): Studi kasus group facebook lembaga survei sosial media. In Seminar Nasional Teknologi Informasi dan Komunikasi (SEMNASTIK), volume 1, pages 203-209, 2018.

[24] Edi Surya Negara and Ria Andryani. A review on overlapping and non-overlapping community detection algorithms for social network analytics. Far East Journal of Electronics and Communications, 18(1):1-27, 2018. 